\title{
Tsafon
}

Revue d'études juives du Nord

$78 \mid 2019$

L'antijudaïsme dans l'Antiquité

\section{Kolinka Ginette (avec Ruggieri Marion), Retour à Birkenau}

Danielle Delmaire

\section{OpenEdition}

1 Journals

Édition électronique

URL : https://journals.openedition.org/tsafon/2646

DOI : $10.4000 /$ tsafon. 2646

ISSN : 2609-6420

Éditeur

Association Jean-Marie Delmaire

Édition imprimée

Date de publication : 1 décembre 2019

Pagination : 183-184

ISSN : 1149-6630

\section{Référence électronique}

Danielle Delmaire, « Kolinka Ginette (avec Ruggieri Marion), Retour à Birkenau », Tsafon [En ligne], 78।

2019, mis en ligne le 01 décembre 2019, consulté le 25 juin 2021. URL : http://

journals.openedition.org/tsafon/2646 ; DOI : https://doi.org/10.4000/tsafon.2646

Ce document a été généré automatiquement le 25 juin 2021.

Tsafon. Revues d'études juives du Nord 


\title{
Kolinka Ginette (avec Ruggieri Marion), Retour à Birkenau
}

\author{
Danielle Delmaire
}

\section{RÉFÉRENCE}

Paris, Grasset, 99 p., $13 €$

1 Avec Simone Veil, Marceline Rozenberg devenue par mariages Loridan puis Ivens, Ginette Kolinka née Cherkasky fait partie du convoi 71 du 13 avril 1944 dans lequel se trouvaient également 33 des enfants de la Maison d'Izieu ainsi que leur monitrice Léa Feldblum. Le 13 mars 1944, elle avait été arrêtée en Avignon, où la famille avait trouvé refuge, avec son père âgé de 60 ans, son petit frère de 12 ans. Tous deux furent immédiatement gazés à l'arrivée. Durant de longues décennies, Ginette Kolinka a vendu des articles de bonneterie sur le marché d'Aubervillers sans jamais s'appesantir sur son passé mais sans jamais l'oublier. Puis au début des années 2000, elle se décida à rejoindre une association d'anciens déportés et commença à parler, à témoigner devant un jeune public scolaire, parcourant toute la France afin de sensibiliser les jeunes générations aux conséquences meurtrières des idéologies racistes. Elle accepta même d'accompagner des élèves dans leur voyage à Auschwitz. De ce « retour à Birkenau » est né ce livre de mémoire.

2 À l'arrivée en mars 1944, ce fut la stupéfaction devant la désolation du lieu, la brutalité des gardes et l'état de délabrement des internés. Au « retour à Birkenau » ce fut aussi la stupéfaction : " c'est beau » s'étonne-t-elle ; l'endroit est tellement agréable qu'elle croise une joggeuse insouciante qui foule « cette terre grasse et méconnaissable, qui a vu tant de morts » (p. 9). Il fait doux et les enfants du voisinage « jouent sur leur toboggan »! C'est trop beau : «Il ne faut pas retourner à Birkenau au printemps » (p. 10). Car au printemps 1944 (le 16 avril), lorsqu'elle débarque du train de déportation, elle ne pouvait pas comprendre ce qu'elle voyait. Lors de ce "retour ", elle évoque une naïveté qui fait écran sur la réalité : la fumée, c'est celle de l'usine ! Mais vite, très vite, 
ce qu'actuellement elle nomme " naïveté " disparut, remplacée par la honte : le tatouage (78 599), la nudité, les coups et les hurlements... Ce qu'elle avait cru être des chiffons sont des cadavres! Alors elle a vite compris qu'il fallait «ne jamais me révolter, tout accepter » (p. 31), qu'il fallait aussi « organiser " pour survivre et surtout : «perdre le moral, c'est précipiter la mort » (p. 42). Au « retour à Birkenau », sans gêne cette fois, elle évoque la disparition de ses règles, ce que les femmes rescapées d'Auschwitz et d'autres camps ont trop souvent occulté, par pudeur probablement alors que c'était la conséquence de la maltraitance, tout comme la maigreur, les maladies.

Elle se souvient de la présence de Simone (Jacob-Veil) et Marceline (RozenbergLoridan-Ivens), l'une " trop belle " et l'autre " dégourdie ", ses amies qui l'ont accompagnée dans sa déchéance et qui l'ont soutenue.

4 Après Birkenau, elle survécut au transfert à Bergen-Belsen puis au camp de Theresienstdat qui fonctionnait encore et duquel elle fut libérée : comateuse, elle fut évacuée sur une civière ne pesant que $26 \mathrm{~kg}$.

Ce témoignage s'ajoute à d'autres tout aussi poignants et qui veulent interpeller les générations actuelles sur les dangers de la radicalisation des idées racistes et de l'antisémitisme renaissant. Mais dans sa brièveté, il permet de vaincre l'appréhension d'un adolescent dans sa découverte de la Shoah. Il renforce aussi la réflexion sur des événements actuels. En cela, le "retour à Birkenau » éveille les consciences ce que Ginette Kolinka a très bien réussi. 